\title{
DISABILITY ALLIANCES AND ALLIES
}




\section{RESEARCH IN SOCIAL SCIENCE AND DISABILITY}

\section{Series Editors: Sharon N. Barnartt and Barbara M. Altman}

\section{Recent Volumes:}

Volume 1: $\quad$ Expanding the Scope of Social Science Research on Disability Edited by Sharon N. Barnartt and Barbara M. Altman

Volume 2: $\quad$ Exploring Theories and Expanding Methodologies: Where We Are and Where We Need to Go - Edited by Sharon N. Barnartt and Barbara M. Altman

Volume 3: Using Survey Data to Study Disability: Results from the National Health Interview Survey on Disability - Edited by Barbara M. Altman, Sharon N. Barnartt, Gerry E. Hendershot and Sheryl A. Larson

Volume 4: $\quad$ International Views on Disability Measures: Moving Toward Comparative Measurement - Edited by Barbara M. Altman, Sharon N. Barnartt, Gerry E. Hendershot and Sheryl Larson

Volume 5: Disability as a Fluid State - Edited by Sharon N. Barnartt

Volume 6: Disability and Community - Edited by Allison C. Carey and Richard K. Scotch

Volume 7: Disability and Intersecting Statuses - Edited by Sharon N. Barnartt and Barbara M. Altman

Volume 8: $\quad$ Environmental Contexts and Disability - Edited by Sharon N. Barnartt and Barbara M. Altman

Volume 9: What Did We Know and When Did We Know It - Edited by Sara Green and Sharon N. Barnartt

Volume 10: Factors in Studying Employment for Persons with Disability: How the Picture Can Change - Edited by Barbara M. Altman and Sharon N. Barnartt

Volume 11: New Narratives of Disability: Constructions, Clashes, and Controversies - Edited by Sara E. Green and Donileen R. Loseke 
RESEARCH IN SOCIAL SCIENCE AND DISABILITY (RSSD) VOLUME 12

\section{DISABILITY ALLIANCES AND ALLIES: OPPORTUNITIES AND CHALLENGES}

EDITED BY

ALLISON C. CAREY

Shippensburg University, Shippensburg, PA, USA

JOAN M. OSTROVE

Macalester College, St. Paul, MN, USA TARA FANNON

New York City Department of Education, New York, NY, USA

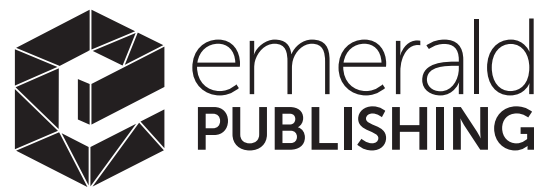

United Kingdom - North America - Japan India - Malaysia - China 
Emerald Publishing Limited

Howard House, Wagon Lane, Bingley BD16 1WA, UK

First edition 2021

Copyright (C) 2021 Emerald Publishing Limited

\section{Reprints and permissions service}

Contact: permissions@emeraldinsight.com

No part of this book may be reproduced, stored in a retrieval system, transmitted in any form or by any means electronic, mechanical, photocopying, recording or otherwise without either the prior written permission of the publisher or a licence permitting restricted copying issued in the UK by The Copyright Licensing Agency and in the USA by The Copyright Clearance Center. Any opinions expressed in the chapters are those of the authors. Whilst Emerald makes every effort to ensure the quality and accuracy of its content, Emerald makes no representation implied or otherwise, as to the chapters' suitability and application and disclaims any warranties, express or implied, to their use.

\section{British Library Cataloguing in Publication Data}

A catalogue record for this book is available from the British Library

ISBN: 978-1-83909-322-7 (Print)

ISBN: 978-1-83909-321-0 (Online)

ISBN: 978-1-83909-323-4 (Epub)

ISSN: 1479-3547 (Series)

\section{ISOQAR certified}

Management System,

awarded to Emerald

for adherence to

Environmental

standard

ISO 14001:2004 


\section{CONTENTS}

List of Tables

vii

About the Contributors ix

List of Contributors xiii

Introduction: Exploring the Opportunities and Challenges of Alliances and Allyship in the Lives of People with Disabilities Allison C. Carey, Tara Fannon and Joan M. Ostrove

\section{PART I \\ STRUCTURES AND \\ SYSTEMS THAT SHAPE ALLIANCES}

Chapter 1 International Rights and Local Realities: Transnational Allies of the Disability Rights Movement in China

Shixin Huang

Chapter 2 Allies, Enemies, or Indifferent? The Disability and Older Persons' Movements under Neoliberalism in Jamaica

Stephen Meyers

Chapter 3 Impasses of Disability Alliance Building in Bulgaria: Successful Phantom Activism and Toxic Grassroots Mobilization Ina Dimitrova

Chapter 4 "I've Used My Wide Array of Skills to Create a Life for Myself": Managing Narratives with Competing Goals in an Arts-based Disability Ally Organization

Melinda Leigh Maconi

Chapter 5 Allyship Changes in American Disability Protests over Five Decades: An Empirical Analysis

Sharon Barnartt 


\section{PART II \\ RELATIONAL DYNAMICS OF \\ ALLIANCE BUILDING}

Chapter 6 Nothing about "Us" without Whom? (Re)Cognizing Alliance between Disabled People and Care Workers in Direct-Funded Attendant Services

Erika Katzman

Chapter 7 Autistic Adult and Non-Autistic Parent Advocates: Bridging the Divide

Helen Rottier and Morton Ann Gernsbacher

Chapter 8 Becoming Allies: The Transmogrification of the Role of American Sign Language/English Interpreters during the Deaf President Now Protest

Mark Halley

Chapter 9 Can We Broaden the Neurodiversity Movement without Weakening It? Participatory Approaches as a Framework for Cross-disability Alliance Building

Kristen Gillespie-Lynch, Patrick Dwyer, Christopher Constantino, Steven K. Kapp, Emily Hotez, Ariana Riccio, Danielle DeNigris, Bella Kofner and Eric Endlich

Chapter 10 A Different Story: Narrative Allyship across Ability 225 Nicki Pombier 


\section{LIST OF TABLES}

\section{Chapter 5}

Table 1. Types of Allies Involved in Protests.

Table 2. Percentage Distributions of Internal Ally Organizations $(\mathrm{N}=1067)$.

Table 3. Percentage Distributions of Organizations by Type of Organization $(\mathrm{N}=799)$.

Table 4. Percentage Distribution of External Groups Involved in Protests $(\mathrm{N}=325)$.

Table 5. Numbers of Individual Protesters, by Type. 120

Table 6. $\quad$ Percentages of Ally Organizations by Decade and Type.

Table 7. Percentages of Protests with Individual Ally Protesters, by Type and Decade.

\section{Chapter 8}

Table 1. Demographic Information of Participants.

\section{Chapter 9}

Table 1. Reflexivity Statements.

Table 2. How Can Tensions within the Neurodiversity Movement Inform Alliance Building?

Chapter 10 
This page intentionally left blank 


\section{ABOUT THE CONTRIBUTORS}

Sharon Barnartt is Professor Emeritus of Sociology at Gallaudet University. She coauthored Deaf President Now: The 1988 Revolution at Gallaudet University (with John Christiansen) and Disability Protests: Contentious Politics 1970- 1999 (with Richard Scotch). She has served as president of the Society for Disability Studies, Chair of the Disability and Society Section of the American Sociological Association, and Chair of the American Sociological Association Status Committee on Persons with Disabilities in Sociology. She is currently a coeditor of Research in Social Science and Disability.

Allison C. Carey is a professor of Sociology at Shippensburg University. She is a coauthor of Allies and Obstacles: Disability Activism and Parents of Children with Disabilities (Temple University Press, 2020, with Pamela Block and Richard Scotch) and the author of On the Margins of Citizenship: Intellectual Disability and Civil Rights in Twentieth Century America (Temple University Press, 2009). She has coedited two volumes, including RSSD's volume 6 Disability and Community (Emerald, 2011, with Richard Scotch).

Christopher Constantino lives in Tallahassee with his wife Megan and son Augustine. He is a person who stutters. He works as a speech-language pathologist and assistant professor at Florida State University. He teaches classes on counseling and stuttering and studies how the subjective experience of stuttering interacts with culture and society.

Danielle DeNigris, $\mathrm{PhD}$, is an Assistant Professor of Psychology at Fairleigh Dickinson University. Earlier, she served as Coordinator for Project REACH at the College of Staten Island, CUNY. Her research is two-pronged: (1) the experiences of autistic undergraduates and (2) the development of temporal cognition in children.

Ina Dimitrova received her $\mathrm{PhD}$ in social and political philosophy from Bulgarian Academy of Sciences, Institute for the Study of Knowledge and Societies, and currently is an associate professor at Plovdiv University "Paisii Hilendarski" in social philosophy and bioethics.

Patrick Dwyer is a psychology graduate student at UC Davis. His research is primarily focused on understanding the sensory experiences of autistic people, both at the group level and the individual level, and he uses electrophysiology and questionnaires to explore auditory processing, cross-modal integration, and attention in autism. 
Eric Endlich, PhD, is a clinical psychologist, educational consultant, and autistic self-advocate who coauthored an international study of 150 older autistic adults. He helps autistic students transition to higher education, provides training on managing a neurodiverse workforce, and writes and presents regularly on related topics.

Tara Fannon is a gender and disability sociologist and interdisciplinary scholar working in disability advocacy. Her research bridges sociology, disability studies, and narrative studies and examines the relationship between self, identities, and social-structural access. She has been an editor of Endangered Bodies NYC and Masculinities 101 blogs and a contributor to others such as Gender \& Society and The Good Men Project. Her academic work has been published in Research in Social Science and Disability, Symbolic Interaction, Disability Studies Quarterly, and the Norton Reader. Her current work focuses on using story-telling in the public sphere as an alliance building tool and medium for advocacy and policy development.

Morton Ann Gernsbacher is a Vilas Research Professor and the Sir Frederic Bartlett Professor of Psychology at the University of Wisconsin-Madison. Her research examines human communication, including typical, atypical, and virtual.

Mark Halley, PhD, NIC is an Assistant Professor of American Sign Language/ English Interpreting at the University of North Florida. He conducted his doctoral research in the Department of Interpretation and Translation at Gallaudet University in Washington, DC. He has also been an interpreter in private practice since 2011 .

Emily Hotez, PhD, is a research scientist at the UCLA Center for Healthier Children, Families and Communities. Her research interests include utilizing participatory and mixed-methods approaches to designing, implementing, and evaluating interventions that reflect the needs, experiences, and priorities of the populations they seek to serve.

Shixin Huang is a $\mathrm{PhD}$ candidate in the Henry M. Jackson School of International Studies, University of Washington. Her research focuses on the disability rights movement in China, especially how local disability organizations and activists deploy the international discourses and approach of disability rights to claim their identity and citizenship on the ground.

Steven K. Kapp is a developmental psychologist. He is a Lecturer in Psychology at the University of Portsmouth with expertise in autism and neurodiversity. His academic background includes psychology, education, public policy, and disability studies, with additional publications in anthropology, medicine, and neuroscience reaching diverse audiences and readerships.

Erika Katzman, $\mathrm{PhD}$, is a registered Occupational Therapist and Assistant Professor in Disability Studies at King's University College (Western University) in 
London, Ontario, Canada. Her research is informed by critical feminist and disability studies. Areas of focus include invisible work, care work, caregiving relationships, occupational justice, and disability representation in health professional education.

Bella Kofner is a senior at the College of Staten Island who is majoring in mathematics education with a minor in disability studies. She is an autistic self-advocate who coleads Project REACH structured group meetings, does participatory research and does presentations about autism (gender inequality in autism and neurodiversity to name one of the many).

Kristen Gillespie-Lynch is an Associate Professor of Psychology at the College of Staten Island \& The Graduate Center (CUNY). In collaboration with autistic people, she coconstructs supports to empower autistic people and reduce stigma. She developed a participatory mentorship program for autistic college students and evaluates autism trainings internationally.

Melinda Leigh Maconi is a doctoral candidate in the Sociology Department at the University of South Florida, United States. Her areas of research include disability, health and illness, education, the arts, and identity. Her current projects examine the ways in which these artists with disabilities incorporate art into their identity.

Stephen Meyers is an Assistant Professor of Law, Societies \& Justice; International Studies; and Disability Studies at the University of Washington, Seattle. His research explores the interaction between grassroots disabled persons organizations and older persons associations with local and international laws and policies in the Global South.

Joan M. Ostrove is a Professor of Psychology and the Director of the Jan Serie Center for Scholarship and Teaching at Macalester College in Saint Paul, Minnesota. Her current research examines the qualities that members of marginalized groups look for in dominant-group allies, specifically in the domains of disability and race. Ostrove has coedited special issues of the Journal of Social Issues and Disability Studies Quarterly, and her work has been published in the Journal of Applied Social Psychology, Feminism \& Psychology, Review of Higher Education, and Journal of Higher Education, among others.

Nicki Pombier is an oral historian, writer, and educator. She is a part-time faculty member at the College of Performing Arts at The New School University and on faculty in the Oral History Master of Arts program at Columbia University. She lives in Brooklyn, New York.

Helen Rottier is a graduate student in disability studies at the University of Illinois at Chicago. Her research focuses on academic ableism, empowering autistic scholars, and radically reimagining autistic knowledge production in and out of the academy. 
Ariana Riccio is a doctoral candidate at the Graduate Center of the City University of New York. Her research interests include design and evaluation of employment and educational transition services for autistic adolescents and young adults, expressions of disability and autistic identity, and engaging in participatory research design. 


\section{LIST OF CONTRIBUTORS}

Sharon Barnartt

Allison C. Carey

Christopher Constantino

Danielle DeNigris

Ina Dimitrova

Patrick Dwyer

Eric Endlich

Tara Fannon

Morton Ann Gernsbacher

Mark Halley

Emily Hotez

Shixin Huang

Steven K. Kapp

Erika Katzman
Department of Sociology, Gallaudet University, Washington, DC, USA

Department of Sociology and Anthropoplogy, Shippensburg University, Shippensburg, PA, USA College of Communications and Information, Florida State University, Tallahassee, FL, USA

Department of Psychology and Counseling, Fairleigh Dickinson University, Madison, NJ, USA

Departments of Philosophy and History, Plovdiv University - Paisii Hilendarski, Plovdiv, Bulgaria Department of Psychology, University of California, Davis, Davis, CA, USA

Independent Scholar and Educational Consultant, Top College Consultant, Needham, MA, USA

New York City Department of Education, New York City, USA

Department of Psychology, University of Wisconsin-Madison, Madison, WI, USA

Department of Exceptional, Deaf, and Interpreter Education, College of Education and Human Services, University of North Florida, Jacksonville, FL, USA

Center for Healthier Children, Families and Communities, University of California, Los Angeles, Los Angeles, CA, USA

Henry M. Jackson School of International Studies, University of Washington, Seattle, WA, USA

Department of Psychology, University of Portsmouth, Portsmouth, Hampshire, UK Department of Interdisciplinary and Disability Studies, King's University College, Western University, London Ontario, Canada 
Bella Kofner

Melinda Leigh Maconi

Stephen Meyers

Joan M. Ostrove

Nicki Pombier

Helen Rottier

Ariana Riccio
School of Education, College of Staten Island City University of New York, New York, NY, USA

Department of Psychology, College of Staten Island \& CUNY Graduate Center - City University New York, NY, USA

Department of Sociology, University of South Florida, Tampa, FL, USA

Department Law, Societies and Justice, University of Washington, Seattle, WA, USA

Department of Psychology and Jan Serie Center for Scholarship and Teaching, Macalester College, Saint Paul, MN, USA

Oral History Master of Arts Program at Columbia University and College of Performing Arts at The New School University, New York, NY, USA

Department of Disability and Human

Development, University of Illinois at Chicago, Chicago, IL, USA

Department of Psychology, CUNY Graduate

Center - City University of New York, New York, NY, USA 